\title{
Fertility Differences Among Developing Countries: Are They Still Related to Family Planning Program Efforts and Social Settings?
}

CONTEXT: In many developing countries, fertility has declined steadily in recent decades, while the average strength of family planning programs has increased and social conditions have improved. However, it is unclear whether the synergistic effect of family planning programs and social settings on fertility, first identified in the 1970s, still holds.

METHODS: Data from 40 developing countries in which Demographic and Health Surveys were conducted in 2003-2010 were used to examine associations among socioeconomic conditions, family planning program effort strength and fertility. Cross-tabulations and multiple regression analyses were conducted.

RESULTS: Variation among countries in scores on the Family Planning Program Effort Index, but not on the Human Development Index, has diminished since the 1970s. On average, fertility levels were lower among countries with better social settings or stronger family planning programs than among those with poorer settings or weaker programs; they were lowest in the presence of both good social settings and strong programs. In addition, fertility was positively associated with infant mortality and negatively associated with female education, but not associated with poverty. About half of the 2.3-birth difference in fertility between countries in Sub-Saharan Africa and those elsewhere can be attributed to differences in program efforts and social settings.

CONCLUSIONS: Policies focused on improving levels of female education, reducing infant mortality and improving family planning services can be expected to have mutually reinforcing effects on fertility decline. International Perspectives on Sexual and Reproductive Health, 2012, 38(1):15-22, doi: 10.1363/3801512

\section{By Anrudh K. Jain and John A. Ross}

Anrudh K. Jain is distinguished scholar, Population Council, New York. John A. Ross is an independent consultant, Wallkill, NY, USA.
National family planning programs, which emerged during the 1960s and 1970s, were greeted skeptically by some, who doubted that they would affect fertility behavior. However, extensive evidence subsequently suggested that these programs do reduce fertility, especially when socioeconomic conditions are relatively favorable and sufficient infrastructure (including administrative, staff and logistical support) for the implementation of mass programs exists. ${ }^{1-6}$

In the years since, family planning programs have come under scrutiny, notably at the 1994 Cairo International Conference on Population and Development, where leaders strongly advocated that programs be broadened to embrace aspects of reproductive health beyond contraceptive use. The conference's impact is hard to gauge, but some countries may have modified programs that were narrowly focused on fertility change. Furthermore, the organization of family planning and related programs in some countries has been sharply modified through decentralization of the health ministry or to address the massive demands of HIV/ AIDS programs. Nonetheless, average global scores on the Family Planning Program Effort Index-a survey-based assessment that measures national program strength-have risen steadily since 1972, albeit more slowly in the last decade than previously. ${ }^{7}$ During these same years, fertility has declined substantially and contraceptive use has risen in many countries. ${ }^{8}$
Given these changes, as well as the passage of time, the relationship of national fertility levels to the strength of family planning programs and to socioeconomic context warrants reexamination. In the long term, economic development is expected to lead to fertility decline, as it did in North America and Western Europe. At the same time, it seems clear that a good family planning program can reduce fertility, even in very poor countries, as in Bangladesh and Northern Ghana. ${ }^{9-11}$ Nonetheless, studies conducted prior to the 1994 Cairo meeting found that family planning programs are most effective when a strong program is implemented in a good social setting (e.g., one in which literacy, life expectancy and income are high). ${ }^{1-6}$ These results were consistent with the Cairo conference's program of action, ${ }^{12}$ which called for countries to reduce gender inequality in health, education and economic opportunities and to provide contraceptive services within the context of reproductive health. Strong programs of this nature can reduce levels of unwanted pregnancy by satisfying overt demand for contraceptives; moreover, as new reproductive health technologies diffuse through a society, women who are ambivalent about or have latent interest in family planning may become motivated to exert control over their fertility by adopting contraception. In addition, new demand for contraceptives can be created as improvements in education, health and socioeconomic status occur. 
FIGURE 1. Variation among family planning program effort scores in 40 countries, 1972-2009

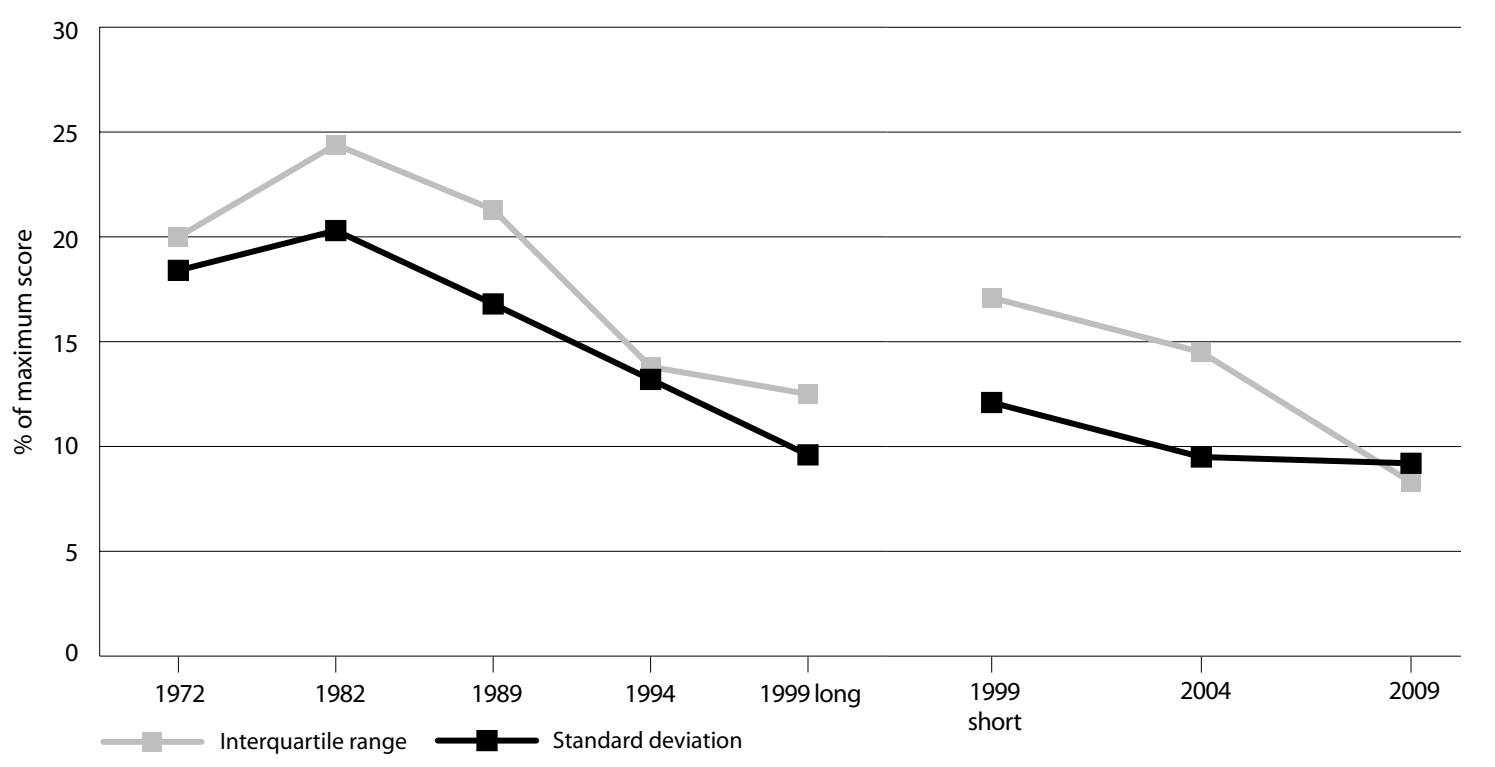

In this study, we use recent data on fertility, social settings and family planning program effort to ascertain the extent to which the main findings of studies conducted prior to 1994 remain valid-that is, that family planning programs are most effective when they are strong and operate under favorable social conditions.

\section{METHODS}

\section{Data and measures}

We examined data from 40 developing countries in which a Demographic and Health Survey (DHS) had been conducted between 2003 and 2010. This range provides an approximate correspondence between the year family planning program effort was assessed (2004) and the years covered by the DHS fertility measure, which is based on births during the three years prior to the survey. The 2010 date also permits the inclusion of additional countries with recent surveys. The 40 countries are not representative of all developing countries; however, focusing on those that have conducted a DHS offers the advantage that the surveys shared a uniform methodology, including the use of an identical reference period for the fertility measure. In addition, the series includes many of the world's leastdeveloped countries; they are of particular interest because they typically have a high level of unmet need for family planning and, in some cases, have just begun the transition toward increased contraceptive use and lower fertility.

\footnotetext{
*The Human Development Index is a composite measure consisting of indicators of health, education and gross domestic product (reference 13).

†The 2004 survey included assessments from 1,037 experts from 82 countries, an average of 13 per country. Respondents included program staff, personnel of international organizations residing in the country, local staff of nongovernmental organizations and employees of local academic and research organizations (sources: reference 15 and Ross J Stover J and Adelaja D, Family planning programs in 2004: new assessments in a changing environment, International Family Planning Perspectives, 2007, 33(1):22-30.
}

Finally, the 40 countries account for a substantial share of the developing world's population (outside of China), and include four of the other most populous countries in AsiaIndia, Indonesia, Bangladesh and Pakistan-as well as the four most populous countries in Sub-Saharan AfricaNigeria (home to one-fifth of Sub-Saharan Africa's population), Ethiopia, Tanzania and Kenya.

Studies that have examined the relationship between family planning programs and fertility have used a variety of socioeconomic indicators, including the Human Development Index, ${ }^{*}$ literacy rates, primary and secondary school enrollment, life expectancy, infant mortality rate, gross national product per capita, proportion of residents living in urban settings and proportion of the male labor force not working in agriculture. Of these, we chose the Human Development Index as a composite indicator of social setting; the individual indicators we used were the World Bank's indicator of poverty level (proportion of the population living on less than US\$2 per day), ${ }^{13}$ female education (proportion of young women aged 15-19 who had received some secondary education) and the infant mortality rate. The Human Development Index scores ${ }^{14}$ and the World Bank data on poverty level ${ }^{13}$ are for 2005; DHS StatCompiler data on the total fertility rate (TFR), female education and infant mortality are for the 2003-2010 survey dates listed in Appendix Table 1 (see page 22). ${ }^{8}$

Scores from the 2004 National Family Planning Program Effort Index were based on measures of the intensity and types of effort exerted by national family planning programs. ${ }^{7}$ In each country, expert respondents rated 31 aspects of the national program using a 10-point scale; these ratings were combined and the total scores were rescaled as a percentage of the maximum, yielding a final score ranging from 0 to $100 .^{\dagger}$ Each country's effort score (along with its values for the other indicators used in the analysis) are provided in Appendix Table 1. 


\begin{tabular}{|c|c|c|c|c|c|c|c|}
\hline Social setting score* & Strong ( $\geq 54)$ & & Moderate (46.0-5 & & Weak $(<46)$ & & All \\
\hline All & & 3.9 & & 4.2 & & 5.3 & 4.5 \\
\hline $\begin{array}{l}\text { Good } \\
(\geq 57)\end{array}$ & $\begin{array}{l}\text { Namibia } \\
\text { Egypt } \\
\text { Indonesia } \\
\text { Morocco } \\
\text { Mean }\end{array}$ & $\begin{array}{l}3.6 \\
3.0 \\
2.6 \\
2.5 \\
\\
\\
2.9\end{array}$ & $\begin{array}{l}\text { Jordan } \\
\text { Cambodia } \\
\text { Philippines } \\
\text { India } \\
\text { Colombia } \\
\text { Dominican Rep. } \\
\text { Mean }\end{array}$ & $\begin{array}{l}3.8 \\
3.4 \\
3.3 \\
2.7 \\
2.4 \\
2.4 \\
3.0\end{array}$ & $\begin{array}{l}\text { Congo } \\
\text { Bolivia } \\
\text { Honduras }\end{array}$ & $\begin{array}{l}4.8 \\
3.5 \\
3.3\end{array}$ & 3.2 \\
\hline $\begin{array}{l}\text { Medium } \\
(48.0-56.9)\end{array}$ & $\begin{array}{l}\text { Benin } \\
\text { Pakistan } \\
\text { Ghana } \\
\text { Nepal } \\
\text { Bangladesh } \\
\text { Mean }\end{array}$ & $\begin{array}{l}5.7 \\
4.1 \\
4.0 \\
3.1 \\
2.7 \\
\\
3.9\end{array}$ & $\begin{array}{l}\text { Madagascar } \\
\text { Kenya } \\
\text { Lesotho }\end{array}$ & $\begin{array}{l}4.8 \\
4.6 \\
3.5\end{array}$ & $\begin{array}{l}\text { Uganda } \\
\text { Nigeria } \\
\text { Tanzania } \\
\text { Cameroon } \\
\text { Haiti } \\
\text { Swaziland } \\
\text { Mean }\end{array}$ & $\begin{array}{l}6.7 \\
5.7 \\
5.7 \\
5.0 \\
3.9 \\
3.9 \\
5.2\end{array}$ & 4.5 \\
\hline $\begin{array}{l}\text { Poor } \\
(<48)\end{array}$ & $\begin{array}{l}\text { Burkina Faso } \\
\text { Mozambique }\end{array}$ & $\begin{array}{l}5.9 \\
5.5\end{array}$ & $\begin{array}{l}\text { Mali } \\
\text { Malawi } \\
\text { Guinea } \\
\text { Senegal }\end{array}$ & $\begin{array}{l}6.6 \\
6.0 \\
5.7 \\
4.9\end{array}$ & $\begin{array}{l}\text { Niger } \\
\text { Chad } \\
\text { Dem.Rep.Congo } \\
\text { Zambia } \\
\text { Liberia } \\
\text { Rwanda } \\
\text { Ethiopia } \\
\text { Mean }\end{array}$ & $\begin{array}{l}7.0 \\
6.3 \\
6.3 \\
6.2 \\
5.9 \\
5.5 \\
5.4 \\
6.1\end{array}$ & 5.9 \\
\hline
\end{tabular}

*Based on Human Development Index score.

\section{Analyses}

We used two approaches to study the associations of family planning program effort and social setting with fertility: cross-tabulation and multiple regression analyses. In both, we employed two indicators of social setting-one with an economic component, one without-to examine whether the inclusion of an economic indicator changed the results. The first index-the Human Development Indexconsisted of three components: life expectancy, education (proportion of adults who are literate and proportion of school-age children who are attending school) and gross domestic product per capita.* The second index comprised a measure of female education (proportion of young women aged 15-19 with some secondary education) and the infant mortality rate; these correspond closely to two of the three Human Development Index components. In fact, the correlation coefficient between female education and the Human Development Index was 0.85, and that between infant mortality rate and the Human Development Index was -0.85 .

For the cross-tabulation analysis, we classified Human Development Index scores of 57 or greater as good, 48.056.9 as medium and less than 48 as poor. The construction of the second index of social setting required several steps. First, we categorized infant mortality rates of 75 or more deaths per 1,000 live births as high, 50.0-74.9 per 1,000 as medium and fewer than 50 per 1,000 as low. Next, we rated the level of female education in a country as high if at least 65\% of young women aged 15-19 had had some secondary education, as medium if $30.0-64.9 \%$ had had such education and as low if fewer than $30 \%$ had had any secondary schooling. Third, for each of these outcomes, we assigned countries 1-3 points, with lower scores reflecting more favorable conditions (low infant mortality or high female education); we then added the two scores to obtain final scores ranging from 2 to 6 . Finally, we divided the countries into three groups: Those with a combined score of 2 were considered to have a good social setting, those with a total score of 3 or 4 were classified as having a medium social setting and those with a score of 5 or 6 made up the poor group. Therefore, the good category consisted of countries with a high level of female education and a low infant mortality rate; the medium category comprised countries with a high level of female education and a medium or high infant mortality rate, those with a low or medium level of female education and a low infant mortality rate and those with medium rankings on both the education and infant mortality measures. The poor category consisted of countries with a medium ranking on female education and high infant mortality, or a low level of female education and either a medium or high infant mortality rate.

Finally, we created similar categories for program effort index scores. In earlier analyses, ${ }^{15}$ countries with a score of 0-20 were classified as having a very weak or no program, and those with a score of 67 or higher were classified as having a strong program. In 2004, the scores for the 40 countries included in this analysis varied from 23 to 65 , so none had a strong program or a very weak one, according to the earlier definition. Thus, within this reduced range, we categorized countries as having a strong program if

*The components included in the Human Development Index were modified in 2010. 


\section{FIGURE 2. Mean family planning program effort scores, by component, according to social setting*}

70

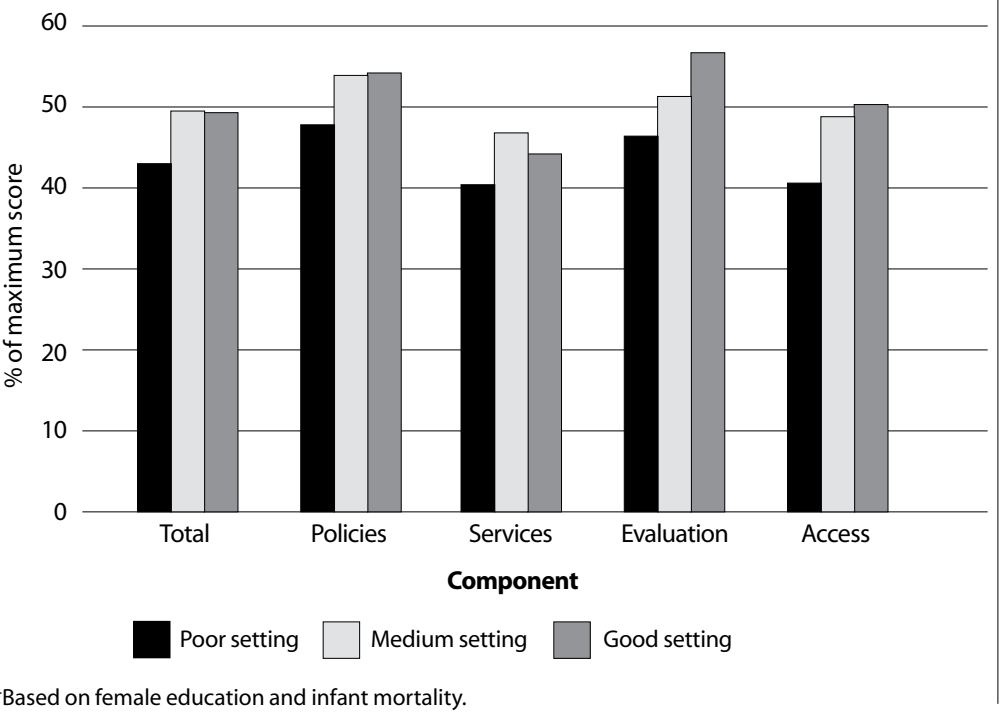

they had a score of at least 54, a medium-strength program if they had a score of 46.0-53.9 and a weak program if they had a score of less than 46.

\section{Diminished Variation in Country Effort Scores}

As the previous paragraph suggests, a major shift has occurred over the years in the range of program effort scores. * Basically, country variation in the scores has diminished considerably, which may have attenuated the past relationships between effort and outcomes. We therefore considered it important to investigate trends in score variation.

Among countries included in prior analyses of program effort (the number of which has varied from 81 to 97), the standard deviation of the average total score has consistently declined, from 23 in 1982 to 11 in 2009. The interquartile range of scores has also diminished, from 39 in 1982 to just 14 in 2009. In another example of diminished variability, about a third of the 92 countries in the 1989 study had either a strong program (14 countries) or a very weak or no program (12 countries), while the remaining two-thirds had programs that were weak (37) or of medium strength (29). But as noted above, by 2004 none of the countries included in the present analysis was classified as having a strong program, a very weak program or no program; 16 had a weak program and 24 had a program of medium strength.

We therefore examined, for these 40 countries, the range

\footnotetext{
*The methodology also has changed. In 1972, a panel of experts rated programs using 15 items; many countries received a score of 0 because they had not initiated a national program. From 1982 to 1999, survey respondents rated program effort on approximately 120 items, using a detailed "long form." A more concise, 30-item "short form" was tested in 1999 , and replaced the long form in subsequent survey rounds.

†The interquartile range is the difference between the 75th and 25th percentiles. The decline in the interquartile range of program effort scores is mirrored by a downward trend in the difference between the maximum and minimum scores.
}

of scores from 1972 onward, measuring variability by both the standard deviation and the interquartile range. These analyses reveal a nearly unbroken decline in the variability, or spread, of the scores (Figure 1, page 16). The principal reason is that many low-scoring countries improved over time, reducing the gaps in scores between these countries and those that had had higher initial scores. That is, countries that scored low in 1972 and 1982 improved much faster than did other countries. A lesser contributor to the decline in variability is that some countries with strong programs (e.g., Korea, Taiwan, Hong Kong, Singapore and Thailand) essentially dismantled their programs as their fertility rates fell below replacement level; moreover, scores in a few other high-scoring countries fell somewhat.

Interestingly, no reduction in variation has taken place for the Human Development Index. The time trend from 1980 through 2010 reveals a steady standard deviation of 0.19 across countries, and a steady interquartile range of about 0.32 (not shown).

\section{RESULTS}

\section{Cross-Tabulations}

When we cross-tabulate the 40 developing countries by their Human Development Index score and the strength of their family planning programs, we find that the average total fertility rate decreases as the social setting improves, from 5.9 among countries with poor social settings to 3.2 among countries with good social settings-a substantial difference of 2.7 births per woman (Table 1, page 17). Similarly, the average total fertility rate declines as the strength of family planning programs improves, from 5.3 among countries with a weak program to 3.9 among those with a strong program, a difference of 1.4 births per woman. These results suggest that the social setting dimension has a stronger effect on the total fertility rate than does program effort. However, changes in fertility are greatest when both social setting and program effort are taken into account. The range along the diagonal, from the lower right (6.1 births per woman) to the upper left ( 2.9 births), is 3.2 births, which exceeds the marginal range for either dimension alone.

The three-way relationship among total fertility rate, program effort and social setting is illustrated by the patterns within columns or rows. At every level of family planning program strength, the average total fertility rate decreases steadily with improvements in social setting-for example, from 5.7 to 3.9 to 2.9 among countries with a strong family planning program, and from 6.1 to 5.2 to 3.9 among countries with a weak program.

Similarly, for any given social setting, the average total fertility rate declines with greater program strength. Among countries with the best social setting, the total fertility rate falls from 3.9 to 3.0 to 2.9 as program effort improves; among those with the worst social setting, the rate falls from 6.1 to 5.8 to 5.7 as program effort increases. Average fertility rates in countries with moderately strong programs are not very different from those in countries with strong programs (4.2 and 3.9); in fact, in earlier analyses, 
countries in both of these groups were classified as having a family planning program of moderate effort. ${ }^{15}$

In an alternate analysis, we used the second social setting index (which lacks an economic component) instead of the Human Development Index. In this analysis (results not shown), the range in the total fertility rate between countries with a good social setting and those with a poor one was slightly smaller than that from the initial analysis in which the social setting score included an economic component ( 2.4 vs. 2.7 points). In addition, the range between the upper left and lower right cells of Table 1 (i.e., between countries with a good social setting and a strong program, and those with a poor setting and weak program) was reduced from 3.2 points to 2.6 points. However, the overall patterns among social setting, program effort and fertility did not change, suggesting that the economic component may not contribute much to the fertility differentials among countries.

Although comparing these gradients to those in earlier analyses ${ }^{15}$ would be of interest, such comparisons are not feasible because of the differences in variable definitions, the diminished range of effort scores and the modifications of the program assessment methodology that were introduced in the 1999 round. $^{7}$

In assessing the possible impact of program strength, we have thus far focused on the total effort score, which comprises four components: policies, services, evaluation and method access. However, the relationship between effort score and social setting (based on infant mortality and female education) may differ by component. For the total score, the main differential in scores is between countries with the poorest social settings and those in the other two groups (Figure 2). The same pattern appears for three of the four index components; only the evaluation component shows a substantial three-way difference. Thus, although better social settings are associated with higher levels of program effort, the difference is primarily between poor and nonpoor contexts.

\section{Regional Differences}

The total fertility rate among the 40 countries varied from 2.4 in Colombia and the Dominican Republic to 7.0 in Niger (Appendix Table 1). Regional differences were striking: The total fertility rate was greater than 4.5 in 21 of the 25 countries in Sub-Saharan Africa, whereas in all countries in other regions it was 4.1 or less. Overall, the average total fertility rate in Africa differed from that in other regions by more than two births-5.4 versus 3.1 (Table 2).

For all of the socioeconomic measures, conditions in Sub-Saharan Africa were poorer than in other countries. The average infant mortality rate in Sub-Saharan African countries was 74 deaths per 1,000 live births, compared with 42 per 1,000 in other countries; only $31 \%$ of females aged 15-19 in Sub-Saharan African countries had some secondary education, compared with $65 \%$ of those in other regions; and $77 \%$ of the population in Sub-Saharan African countries lived on less than US $\$ 2$ per capita, com-
TABLE 2. Mean values for fertility and socioeconomic indicators in 40 developing countries, by region

\begin{tabular}{lccc} 
Indicator & $\begin{array}{l}\text { All } \\
(\mathrm{N}=40)\end{array}$ & $\begin{array}{l}\text { Sub-Saharan } \\
\text { Africa }(\mathrm{N}=25)\end{array}$ & $\begin{array}{l}\text { Other } \\
(\mathrm{N}=15)\end{array}$ \\
\hline $\begin{array}{l}\text { Total fertility rate } \\
\text { Infant mortality rate }\end{array}$ & 4.5 & 5.4 & 3.1 \\
\% of females aged 15-19 with some & 62.2 & 74.3 & 41.9 \\
$\quad$ secondary education & 44.0 & 31.3 & 65.0 \\
\% of population living on < $<$ US 2 per day & 65.0 & 77.2 & 44.8 \\
$\begin{array}{l}\text { Family planning program effort score } \\
\text { Human Development Index score }\end{array}$ & 46.2 & 43.8 & 50.1 \\
& 54.1 & 46.9 & 65.9
\end{tabular}

pared with $45 \%$ of the population elsewhere. In addition, family planning program effort scores were lower for countries in Sub-Saharan Africa than for those in other areas (44 vs. 50). Examining program effort scores by component reveals that the deficits in Sub-Saharan African countries apply to all four components (Figure 3).

\section{Multiple Regression Analyses}

In the 40 countries we examined, the total fertility rate was highly correlated with all of the socioeconomic indicators. It was negatively associated with Human Development Index scores, levels of female education and family planning program effort scores, and positively associated with poverty and infant mortality levels (Table 3, page 20). Because social settings and family planning effort scores in SubSaharan African countries differed from those in other areas, we included a dummy variable for region; higher fertility levels were associated with Sub-Saharan African countries.

We created five regression models. In the first model, we examined the association between the composite social setting measure (the Human Development Index) and fertil-

\section{FIGURE 3. Mean family planning program effort scores, by component, according to region}

$$
70
$$

60

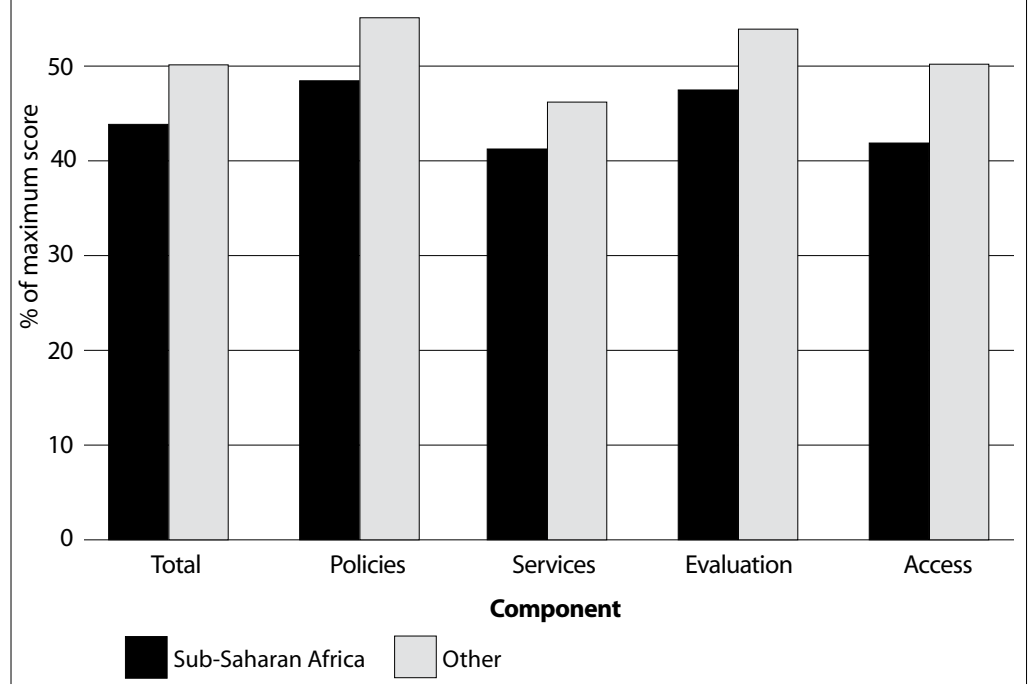




\begin{tabular}{|c|c|c|c|c|c|c|}
\hline \multirow{2}{*}{ Indicator } & \multirow{2}{*}{$\begin{array}{l}\text { Correlation } \\
\text { coefficient }\end{array}$} & \multicolumn{5}{|c|}{ Regression coefficient } \\
\hline & & Model 1 & Model 2 & Model 3 & Model 4 & Model 5 \\
\hline \multicolumn{7}{|l|}{ Human Development } \\
\hline Index & $-.822^{* * *}$ & $-.054^{* * *}$ & na & na & na & na \\
\hline Poverty & $.664^{* * *}$ & na & .044 & na & na & na \\
\hline Infant mortality rate & $.730^{* * *}$ & na & .006 & .008 & na & $.019^{*}$ \\
\hline Female education & $-.757^{* * *}$ & na & $-.017^{*}$ & $-.018^{*}$ & $-.021^{* *}$ & $-.026 * *$ \\
\hline Program effort scores & $-.456^{* *}$ & $-.031^{*}$ & $-.026+$ & $-.026^{*}$ & $-.028^{*}$ & $-.032^{*}$ \\
\hline Sub-Saharan Africa & $.807^{* * *}$ & $1.071^{* *}$ & $1.247^{* *}$ & $1.279^{* *}$ & $1.409^{* * *}$ & na \\
\hline Constant (a) & & 8.246 & 5.109 & 5.239 & 5.897 & 6.017 \\
\hline$R^{2}$ & & .802 & .777 & .775 & .768 & .683 \\
\hline
\end{tabular}

ity, while also controlling for program effort and region. All three measures were related to fertility; the regression coefficients indicate that an increase of 10 points in a country's Human Development Index score was associated with a reduction of 0.5 births per woman in the total fertility rate, while an increase of 10 points in program effort scores was associated with a reduction of 0.3 births. We noted earlier that the average total fertility rate for countries in Sub-Saharan Africa was 2.3 births higher than that in other countries; after we controlled for program effort and $\mathrm{Hu}$ man Development Index score, the regional difference in fertility was reduced to 1.1 births. Thus, about half of the difference in fertility between the two regions is attributable to differences in social settings and program effort.

Because the Human Development Index is a composite index, we created other models to ascertain the relative importance of individual indicators of social setting. In model 2, neither poverty nor infant mortality was associated with the total fertility rate, after adjustment for other predictors of fertility. The high simple correlation between poverty and infant mortality rate (coefficient, 0.741; not shown) may help explain this result. However, when poverty was dropped from the analysis (model 3), infant mortality remained unassociated with fertility. We also tested the reverse approach, dropping infant mortality from the model and retaining poverty; again, poverty was not associated with fertility (not shown). When both poverty and infant mortality were omitted (model 4), the other three determinants (female education, program effort and region) all remained associated with fertility; in fact, for each of these three measures, the magnitudes of the coefficients were generally consistent across models $2-4$, except that the coefficient for region increased when poverty and infant mortality were omitted from the model.

As a further test, we removed education and region from the model to determine whether fertility's associations

*Predicting the total fertility rate from the infant mortality rate and levels of female education and program effort produces a set of estimates that can be matched to the observed values; the correlation coefficient for the two sets is $0.826(p<.001)$. The magnitude of the deviations can reflect the effect on fertility of other factors, such as age at marriage and use of abortion, or the impact of unmeasured variables, such as the HIV/ AIDS epidemic, internal conflicts and cultural factors. with poverty and infant mortality rate would be stronger. Once again, poverty was not associated with fertility (not shown); however, the association between infant mortality and fertility was statistically significant, and the regression coefficient (.027) was greater than before.

Another way to assess the contribution of the economic indicator is to compare the $\mathrm{R}^{2}$ values, or the explanatory powers, of different models. A comparison of models 1 and 3 suggests that the exclusion of the economic component decreased the explanatory power by .027 points, from .802 to .775. A comparison of models 2 and 3 suggests that exclusion of the poverty indicator reduced the explanatory power by .002 points, from .777 to .775 . Clearly, inclusion of an economic component in model 1 or model 2 does not substantially increase their explanatory powers.

These results suggest that the correlation between poverty and the fertility rate is explained by the other three variables; that is, that poor people tend to have higher fertility than others because they also have higher infant mortality, lower levels of education and less access to family planning services.

Finally, we examined the relationship among the second social setting index (comprising infant mortality rate and female education), program effort and fertility (model 5). Region was dropped in this model to make it comparable with the cross-tabulation results. All three determinants were associated with fertility, which is consistent with the results of the cross-tabulation analysis. The regression coefficients indicate that a 10-point decline in a country's infant mortality rate would reduce the total fertility rate by 0.19 births per woman; an increase of 10 percentage points in the proportion of young women receiving some secondary education would reduce the total fertility rate by 0.26 births; and an improvement of 10 percentage points in the strength of family planning program effort would reduce the rate by 0.32 births.* These findings correspond well to the results from model 1 , as the coefficients for program effort are similar in the two models, and the magnitude of the coefficient in model 1 for the Human Development Index (.054) is close to that of the sum of the absolute values of the infant mortality and education measures (.045) in model 5.

\section{CONCLUSION}

The results of the present analysis provide empirical support for the findings from earlier studies-some dating from the mid-1970s-that stronger policy and program efforts to provide information on and access to family planning services are associated with lower fertility levels, and that these relationships are enhanced in favorable social settings. Improvements in a country's overall social conditions, including reduced infant mortality and improved female education, are associated with making the transition from higher to lower fertility; moreover, they create better conditions for the successful implementation of programs.

As low-performing programs have improved over the years, the variability across program effort scores has de- 
clined. This may help explain why the association of program strength with fertility is weaker than that between social setting and fertility when the two are examined separately. An additional factor is that the total fertility rates in some countries, especially those outside of Sub-Saharan Africa, have tapered off and become less responsive to the determinants examined here. It is plausible that the impact of a program is greatest in a country that starts with a good social setting and mounts a strong family planning effort, as occurred in the past, especially in some East Asian countries.

The present analysis suggests that a country's economic setting (measured by proportion of people living in poverty) is less of an influence on fertility rates than are such factors as levels of female education and infant mortality, as the poverty indicator was not related to fertility in multivariate analyses that controlled for the other measures. Use of a different indicator of economic setting (e.g., gross domestic product per capita) may produce a different outcome. However, findings from the cross-classification and multiple regression analyses suggest that exclusion of the economic indicator has little effect on the results.

Clearly, fertility is expected to decline with improvements in social conditions and in the presence of better infant survival. The present analysis also shows that about half of the observed fertility difference of 2.3 births between Sub-Saharan African countries and the other countries can be attributed to regional differences in program efforts and social settings. Although improvements in health, education and family planning programs may not be necessary and sufficient in every country for the fertility transition to occur, the results of this analysis suggest that policies focused on improving female education at the primary school level, reducing infant mortality, and improving the availability and quality of family planning services would have mutually reinforcing effects on fertility, including in Sub-Saharan Africa.

\section{REFERENCES}

1. Freedman R and Berelson B, The record of family planning programs, Studies in Family Planning, 1976, 7(1):1-40.

2. Mauldin WP, Berelson B and Sykes Z, Conditions of fertility decline in developing countries, 1965-75, Studies in Family Planning, 1978, 9(5):90-147.

3. Cutright $P$, The ingredients of recent fertility decline in developing countries, International Family Planning Perspectives, 1983, 9(4): 101-109

4. Lapham RJ and Mauldin WP, Family planning program effort and birthrate decline in developing countries, International Family Planning Perspectives, 1984, 10(4):109-118.

5. Jain AK, The impact of development and population policies on fertility in India, Studies in Family Planning, 1985, 16(4):181-198.

6. Bongaarts J, Mauldin WP and Phillips JF, The demographic impact of family planning programs, Studies in Family Planning, 1990, 21(6):299-310.

7. Ross J and Smith E, The Family Planning Effort Index: 1999, 2004 , and 2009, Washington, DC: Futures Group, 2010.

8. Measure DHS, StatCompiler, no date, <http://www.statcompiler. com>, accessed Dec. 3, 2010
9. Phillips JF et al., Determinants of reproductive change in a traditional society: evidence from Matlab, Bangladesh, Studies in Family Planning, 1988, 19(6):313-334.

10. Debpuur C et al., The impact of the Navrongo Project on contraceptive knowledge and use, reproductive preferences, and fertility, Studies in Family Planning, 2002, 33(2):141-164.

11. Freedman R and Freedman D, The role of family planning programmes as a fertility determinant, in: Phillips JF and Ross JA, eds., Family Planning Programmes and Fertility, Oxford, UK: Clarendon Press, 1992, pp. 10-27.

12. United Nations, Population and Development: Programme of Action Adopted at the International Conference on Population and Development, Cairo, Sept. 5-13, 1994, New York: Department for Economic and Social Information and Policy Analysis, UN, 1995.

13. World Bank, World Development Indicators 2009, Washington DC: World Bank, 2009.

14. United Nations Development Programme, Human Development Report 2009, New York: Palgrave Macmillan, 2009.

15. Mauldin WP and Ross JA, Family planning programs: efforts and results, 1982-89, Studies in Family Planning, 1991, 22(6):350-367.

\section{RESUMEN}

Contexto: En las últimas décadas, la fecundidad ha disminuido de manera continua en muchos países en desarrollo, a la vez que la fortaleza promedio del esfuerzo de los programas de planificación familiar ha aumentado y las condiciones sociales han mejorado. Sin embargo, no es claro si el efecto sinérgico sobre la fecundidad de los programas de planificación familiar y los entornos sociales, que se identificó por vez primera en los años setenta, todavía se mantiene.

Métodos: Se usaron datos de 40 países en los que se llevaron a cabo Encuestas de Demografía y Salud en el período 2003-2010, con el fin de examinar las asociaciones entre las condiciones socioeconómicas, la fortaleza del esfuerzo de los programas de planificación familiar y la fecundidad. Se realizaron tabulaciones cruzadas y análisis de regresión múltiple.

Resultados: La variación entre países en el puntaje del Índice de Esfuerzo del Programa de Planificación Familiar ha disminuido desde los años setenta; sin embargo, la variación en el Índice de Desarrollo Humano no cambió mucho durante el mismo período. En promedio, los niveles de fecundidad fueron más bajos en los países con mejores condiciones sociales o con programas de planificación familiar más fuertes, que en aquellos con entornos más pobres o programas más débiles. Los niveles más bajos de fecundidad se tuvieron en presencia de ambos-tanto las condiciones sociales favorables como los programas fuertes. Además, la fecundidad se asoció positivamente con la mortalid-ad infantil y negativamente con la educación de las mujeres, pero no estuvo asociada con la pobreza. Cerca de la mitad de la diferencia entre la fecundidad de los países de África subsahariana y la de los otros países (unos 2.3 nacimientos más entre las africanas), puede atribuirse a diferencias en los esfuerzos de los programas y los entornos sociales.

Conclusiones: Puede esperarse que las políticas enfocadas en el mejoramiento de los niveles de la educación de las mujeres, en la reducción de la mortalidad infantil y en el mejoramiento de los servicios de planificación familiar, tengan efectos que se refuercen mutuamente para disminuir la fecundidad. 
APPENDIX TABLE 1. Indicators of family planning program effort scores and socioeconomic development for 40 developing countries, in order of descending total fertility rate

\begin{tabular}{|c|c|c|c|c|c|c|c|c|}
\hline Country & Year of DHS & TFR & $\begin{array}{l}\text { Program } \\
\text { effort } \\
\text { score }\end{array}$ & $\begin{array}{l}\text { Infant } \\
\text { mortality } \\
\text { rate }\end{array}$ & Poverty & $\begin{array}{l}\text { Female } \\
\text { education }\end{array}$ & $\begin{array}{l}\text { HDI } \\
\text { score }\end{array}$ & $\begin{array}{l}\text { Sub- } \\
\text { Saharan } \\
\text { Africa }\end{array}$ \\
\hline Niger & 2006 & 7.0 & 27.0 & 81.4 & 85.6 & 10.4 & 33.0 & Yes \\
\hline Uganda & 2006 & 6.7 & 43.0 & 71.1 & 75.6 & 28.0 & 49.4 & Yes \\
\hline Mali & 2006 & 6.6 & 53.3 & 95.8 & 77.1 & 18.3 & 36.1 & Yes \\
\hline Chad & 2004 & 6.3 & 29.0 & 101.7 & 83.3 & 11.0 & 39.4 & Yes \\
\hline Dem.Rep. Congo & 2007 & 6.3 & 31.6 & 91.8 & 79.5 & 42.8 & 37.0 & Yes \\
\hline Zambia & 2007 & 6.2 & 37.0 & 70.4 & 81.5 & 42.9 & 46.6 & Yes \\
\hline Malawi & 2004 & 6.0 & 51.1 & 76.1 & 90.4 & 19.1 & 47.6 & Yes \\
\hline Burkina Faso & 2003 & 5.9 & 58.6 & 81.4 & 81.2 & 13.5 & 36.7 & Yes \\
\hline Liberia & 2009 & 5.9 & 38.0 & 72.6 & 94.8 & 23.5 & 42.7 & Yes \\
\hline Benin & 2006 & 5.7 & 54.0 & 67.0 & 75.3 & 33.0 & 48.1 & Yes \\
\hline Guinea & 2005 & 5.7 & 46.1 & 91.4 & 87.2 & 21.7 & 42.6 & Yes \\
\hline Nigeria & 2008-2009 & 5.7 & 41.6 & 75.3 & 83.9 & 58.8 & 49.9 & Yes \\
\hline Tanzania & 2004 & 5.7 & 45.1 & 68.0 & 96.6 & 10.8 & 51.0 & Yes \\
\hline Mozambique & 2003 & 5.5 & 55.5 & 100.7 & 90.0 & 13.6 & 39.0 & Yes \\
\hline Rwanda & $2007-2008$ & 5.5 & 37.0 & 62.3 & 90.3 & 6.4 & 44.9 & Yes \\
\hline Ethiopia & 2005 & 5.4 & 37.0 & 77.0 & 77.5 & 15.8 & 39.1 & Yes \\
\hline Cameroon & 2004 & 5.0 & 41.8 & 74.1 & 57.7 & 45.4 & 52.0 & Yes \\
\hline Senegal & 2008-2009 & 4.9 & 46.9 & 53.6 & 60.3 & 18.4 & 46.0 & Yes \\
\hline Congo (Brazzaville) & 2005 & 4.8 & 26.3 & 75.5 & 74.4 & 55.1 & 60.0 & Yes \\
\hline Madagascar & $2008-2009$ & 4.8 & 48.4 & 47.9 & 89.6 & 40.1 & 53.2 & Yes \\
\hline Kenya & 2009 & 4.6 & 49.2 & 51.7 & 39.9 & 29.8 & 53.0 & Yes \\
\hline Pakistan & $2006-2007$ & 4.1 & 55.2 & 77.7 & 60.3 & 43.0 & 55.5 & No \\
\hline Ghana & 2008 & 4.0 & 56.0 & 50.3 & 53.6 & 64.7 & 51.2 & Yes \\
\hline Haiti & 2005-2006 & 3.9 & 35.8 & 57.3 & 72.1 & 40.0 & 52.6 & No \\
\hline Swaziland & 2006 & 3.9 & 40.1 & 85.5 & 81.0 & 54.9 & 56.7 & Yes \\
\hline Jordan & 2009 & 3.8 & 50.1 & 23.1 & 3.5 & 97.3 & 76.4 & No \\
\hline Namibia & 2006-2007 & 3.6 & 55.0 & 46.1 & 62.2 & 68.1 & 67.2 & Yes \\
\hline Bolivia & 2008 & 3.5 & 36.1 & 49.8 & 30.3 & 70.2 & 72.3 & No \\
\hline Lesotho & 2004 & 3.5 & 47.6 & 91.0 & 62.2 & 37.5 & 50.8 & Yes \\
\hline Cambodia & 2005 & 3.4 & 46.0 & 65.6 & 68.2 & 42.1 & 57.5 & No \\
\hline Honduras & 2005 & 3.3 & 45.2 & 23.4 & 29.7 & 49.1 & 72.5 & No \\
\hline Philippines & 2008 & 3.3 & 46.9 & 24.9 & 45.0 & 84.9 & 74.4 & No \\
\hline Nepal & 2006 & 3.1 & 57.4 & 47.9 & 77.6 & 53.8 & 53.7 & No \\
\hline Egypt & 2008 & 3.0 & 54.2 & 24.5 & 18.4 & 85.2 & 69.6 & No \\
\hline Bangladesh & 2007 & 2.7 & 64.4 & 51.5 & 81.3 & 68.9 & 52.7 & No \\
\hline India & 2005-2006 & 2.7 & 48.7 & 57.0 & 75.6 & 64.7 & 59.6 & No \\
\hline Indonesia & 2007 & 2.6 & 56.4 & 34.2 & 52.4 & 78.8 & 72.3 & No \\
\hline Morocco & $2003-2004$ & 2.5 & 59.5 & 40.4 & 14.0 & 46.0 & 64.0 & No \\
\hline Colombia & 2005 & 2.4 & 50.0 & 18.7 & 27.9 & 84.0 & 79.5 & No \\
\hline Dominican Rep. & 2007 & 2.4 & 46.2 & 32.1 & 15.1 & 67.3 & 76.5 & No \\
\hline
\end{tabular}

Notes: Infant mortality rate is number of infant deaths per 1,000 live births. Poverty refers to the percentage of the population living on less than $\$$ US2 per day. Female education refers to the percentage of females aged 15-19 with some secondary education. Human Development Index scores are for 2005, except for Haiti (2006); scores are multiplied by 100 for ease of comparison. DHS=Demographic and Health Survey. TFR=Total fertility rate. $\mathrm{HDI}=$ Human Development Index. Sources: Total fertility rate, infant mortality rate and female education-reference 8; family planning program effort scores-reference 7; poverty-reference 13; HDI scores-reference 14.

\section{RÉSUMÉ}

Contexte: Dans beaucoup de pays en développement, la fécondité enregistre une baisse régulière depuis quelques décennies, tandis que se renforce la solidité moyenne des programmes de planification familiale et que s'améliorent les conditions sociales. Il n'est cependant pas clair si l'effet synergique des programmes de planification familiale et des contextes sociaux sur la fécondité, tel qu'identifié dans les années 1970, reste probant.

Méthodes: Les données de 40 pays en développement soumis à l'Enquête démographique et de santé durant la période 2003-2010 servent à examiner les associations entre les conditions socioéconomiques, la force de l'effort programmatique de planification familiale et la fécondité. L'étude procède par tableaux croisés et analyses de régression multiple.

Résultats: La variation entre les cotes nationales à l'échelle du Family Planning Program Effort Index (indice d'effort programmatique de planification familiale), mais pas à celle de l'Indice de développement humain, a diminué depuis les années 1970. En moyenne, les niveaux de fécondité sont moindres dans les pays dotés de meilleurs contextes sociaux ou de programmes de planification familiale plus solides, par rapport à ceux à contextes et programmes plus faibles. Ils sont les plus faibles en présence, à la fois, de bonnes conditions sociales et de programmes solides. De plus, la fécondité présente une association positive avec la mortalité infantile et négative avec l'instruction des filles, mais elle n'en présente aucune avec la pauvreté. Environ la moitié de la différence de fécondité de 2,3 naissances entre les pays d'Afrique subsaharienne et les autres peut être attribuée aux différences d'effort programmatique et de contexte social.

Conclusions: On peut attendre des politiques axées sur l'amélioration des niveaux d'instruction des filles, la réduction de la mortalité infantile et l'amélioration des services de planification familiale des effets de renforcement mutuel sur le déclin de la fécondité.

Author contact: ajain@popcouncil.org 